\title{
COMPOSIÇÃO QUÍMICA, PRODUÇÃO E QUALIDADE DO CAFÉ FERTILIZADO COM DIFERENTES FONTES E DOSES DE NITROGÊNIO
}

\begin{abstract}
RESUMO - Conduziu-se este experimento com a finalidade de se analisar o efeito da adubação nitrogenada sobre a produção e qualidade do café (Coffea arabica L). O delineamento experimental foi em blocos casualizados, no esquema de parcelas subdivididas, utilizandose seis fontes de nitrogênio $(\mathrm{N})$ : calcionamida, nitrato de potássio, nitrocálcio, sulfato de amônio, uréia e nitrato de amônio, nas parcelas, e quatro doses de $\mathrm{N}(0,80$, 160 e $320 \mathrm{~kg} \mathrm{ha}^{-1}$ ) aplicadas nas subparcelas, com três blocos. Avaliaram-se a produção e as variáveis: atividade da polifenoloxidase, acidez titulável total, açúcares totais, compostos fenólicos totais, ácidos clorogê-
\end{abstract}

\author{
MARCELO RIBEIRO MALTA ${ }^{1}$ \\ MARCELO RIBEIRO MALTA
FRANCISCO DIAS NOGUEIRA
FR \\ PAULO TÁCITO GONTIJO GUIMARÃES ${ }^{2}$ \\ PAULO TÁCITO GONTJO GUIMARÃ
}

TERMOS PARA INDEXAÇÃO: Adubação nitrogenada, produção, qualidade do café, composição química, Coffea arabica.

nicos totais, cafeína e prova de xícara. Não houve resposta significativa de produção às fontes e doses de $\mathrm{N}$. Observou-se redução na qualidade do café ao utilizar-se nitrocálcio e nitrato de amônio como fontes de N. Quanto às doses utilizadas, as fontes de $\mathrm{N}$ apresentaram efeitos diferenciados em relação à composição química e qualidade do café; entretanto, observou-se, pelas análises da atividade enzimática da polifenoloxidase, acidez titulável total, ácidos clorogênicos totais e compostos fenólicos totais, que doses mais elevadas de sulfato de amônio têm efeito negativo sobre a qualidade dos grãos.

\section{CHEMICAL COMPOSITION, YIELD AND QUALITY OF THE FERTILIZED COFFEE WITH DIFFERENT SOURCES AND DOSES OF NITROGEN}

\begin{abstract}
This experiment was conducted to analyze the effect of nitrogen fertilization on coffee yield and quality (Coffea arabica $L$ ). The experimental design was a randomized complete-block with the splitplot scheme, in which six sources of nitrogen $(\mathrm{N})$ were used: calcionamida, potassium nitrate, calcium nitrate, ammonium sulphate, urea and ammonium nitrate in the plots combined with four doses of $\mathrm{N}(0,80,160$ and $320 \mathrm{~kg} \mathrm{ha}^{-1}$ ) applied in the subplots, with three replications. Yield and qualitative variables such as polyphenoloxidase activity, total titrable acidity, total sugars, total phenolic compounds, chlorogenic acids,
\end{abstract}

caffeine and sensorial analysis were evaluated. There was no response of yield to $\mathrm{N}$ sources and doses. Coffee quality reduction was observed when calcium nitrate and ammonium nitrate were used. Regarding the doses used, the $\mathrm{N}$ sources presented differentiated effects on the coffee quality; however, it was observed by the analyses of the polyphenoloxidase activity, total titrable acidity, total chlorogenic acids and total phenolic compounds, that higher doses of ammonium sulphate had a negative effect on both chemical composition and quality of the grain.

INDEX TERMS: Nitrogen fertilization, yield, coffee quality, chemical composition, Coffea arabica.

1. Engenheiro Agrônomo, M.Sc., Empresa de Pesquisa Agropecuária de Minas Gerais (EPAMIG), Caixa Postal 176, 37200-000, Lavras, MG. mrmalta@epamig.ufla.br.

2. Engenheiros Agrônomos, D.Sc., Empresa de Pesquisa Agropecuária de Minas Gerais (EPAMIG). 


\section{INTRODUÇÃO}

Os compostos químicos nos grãos de café são reflexos de uma série de atributos que, somados, conferem ao café sabor e aroma peculiares. Entre eles, podem-se destacar fatores genéticos e ambientais e as condições de manejo na produção e processamento póscolheita (CLIFORD, 1985; PRETE, 1992). Em se tratando das condições de manejo, as adubações e o estado nutricional da planta podem influenciar a composição do grão cru e, conseqüentemente, a qualidade da bebida (SILVA, 1995).

O nitrogênio geralmente é o nutriente mais exigido pelas culturas, tendo inúmeras funções, como estimular a formação e o desenvolvimento de gemas floríferas e frutíferas, aumentar a vegetação, o perfilhamento e os teores de proteínas. Além disso, é componente estrutural de aminoácidos e proteínas, bases nitrogenadas e ácidos nucléicos, enzimas, coenzimas e vitaminas, pigmentos e outros produtos secundários (MALAVOLTA et al. 1997).

$\mathrm{Na}$ maioria das regiões cafeeiras, o nitrogênio, com freqüência, é um dos nutrientes mais exigidos na produção. A indicação das fontes de $\mathrm{N}$ mais adequadas para cada caso específico, a dosagem e a forma correta de utilização revestem-se de certa complexidade, em decorrência da alta mobilidade desse nutriente no solo e de uma possível ocorrência de efeitos secundários negativos sobre o solo e a planta, além de implicações de ordem econômica.

Pouca importância tem sido dada ao estado nutricional do cafeeiro, correlacionando-o com a composição mineral e a formação de compostos no grão e, conseqüentemente, com a qualidade do café. A composição mineral do grão pode variar com o estado nutricional do cafeeiro e a quantidade de compostos orgânicos, como a celulose, hemicelulose, óleos, trigonelina, ácido clorogênico e compostos nitrogenados; também depende do local de cultivo, variedade do café, adubações, entre outros fatores. O equilíbrio na combinação desses compostos para a formação do sabor e aroma é importante para a obtenção de bebida de boa qualidade (AMORIM, 1968; CARVALHO et al., 1997).

Grande parte das pesquisas envolvendo o $\mathrm{N}$ está relacionada com o aumento da produtividade que esse nutriente pode exercer sobre o cafeeiro, as quais não fazem referências sobre a influência da adubação nitrogenada na qualidade da bebida. Essa adubação retarda a maturação dos frutos do cafeeiro, e frutos verdes dão bebida de qualidade inferior (PIMENTA, 1995; PEREIRA, 1997). Entretanto, uma adubação desequilibrada de $\mathrm{N}$ pode causar prejuízos, mesmo colhendo-se somente café no estádio cereja (AMORIM et al., 1967). Para alguns autores, a adubação nitrogenada aumenta o teor de $\mathrm{N}$ no grão, havendo correlação negativa entre esse e a qualidade da bebida (AMORIM et al., 1973). Entretanto, Santinato et al. (1996), estudando o efeito do salitre potássico sobre diversas características do cafeeiro, não observaram efeito negativo desse fertilizante nitrogenado na qualidade do café.

Mediante a constatação de poucas e contraditórias pesquisas relacionadas à adubação nitrogenada com a qualidade do café, objetivou-se verificar o efeito de diferentes fontes e doses de N sobre a produção, composição química dos grãos de café e, conseqüentemente, sobre sua qualidade.

\section{MATERIAL E MÉTODOS}

O experimento foi conduzido em um Latossolo Vermelho-Distroférrico, na Fazenda Experimental da Empresa de Pesquisa Agropecuária de Minas GeraisEPAMIG, em São Sebastião do Paraíso-MG, utilizandose a cultivar Topázio (MG 1190), de Coffea arabica L. Instalou-se o experimento em fevereiro de 1996, com uma planta por cova, no espaçamento de $3,5 \times 0,7 \mathrm{~m}$. O delineamento experimental foi em blocos casualizados, no esquema de parcelas subdivididas, utilizando-se seis fontes de nitrogênio: calcionamida (CAL), nitrato de potássio (NIPO), nitrocálcio (NICA), sulfato de amônio (SUA), uréia e nitrato de amônio (NIA), nas parcelas, e quatro doses de $\mathrm{N}\left(0,80,160\right.$ e $\left.320 \mathrm{~kg} \mathrm{ha}^{-1}\right)$ aplicadas nas subparcelas, com três blocos. A unidade experimental foi constituída de duas linhas de oito covas, formando 16 covas por unidade, sendo a unidade útil às seis covas centrais. A adubação básica foi realizada segundo as recomendações da Comissão de Fertilidade do Solo do Estado de Minas Gerais (CFSEMG, 1989). As análises químicas e sensoriais para a avaliação da composição química e qualidade do café foram realizadas no Laboratório de Qualidade do Café Dr. Alcides Carvalho, da Empresa de Pesquisa Agropecuária de Minas Gerais/EPAMIG, em Lavras-MG.

As amostras de café utilizadas foram do ano agrícola de 2000/01. Foram avaliadas as produções de seis plantas úteis, colhidas por derriça no pano, quando apresentavam aproximadamente $5 \%$ de frutos verdes. A quantidade de café limpo por parcela útil foi então convertida em produção de sacas de $60 \mathrm{~kg}$ por hectare. Todos os parâmetros qualitativos, com exceção da avaliação sensorial, foram determinados em amostras de grãos crus de café beneficiado, moídos em moinho tipo Croton, em peneira de $0,60 \mathrm{~mm}$. As avaliações realizadas foram: atividade da polifenoloxidase, acidez titulável 
total, açúcares totais, compostos fenólicos totais, ácidos clorogênicos totais e cafeína.

Os açúcares totais foram extraídos pelo método de Lane-Enyon (AOAC, 1970) e determinados pela técnica de Somogy, adaptada por Nelson (1944). A obtenção do extrato enzimático utilizado na determinação da atividade da polifenoloxidase foi feita por meio da adaptação do processo de extração descrito por Draetta e Lima (1976) e determinada pelo método descrito por Ponting e Joslyng (1948), utilizando-se extrato de amostra sem DOPA (L-3,4-Dihydroxyphenyl-alanine) como branco (CARVALHO et al., 1994). A acidez titulável foi determinada segundo a Association of Official of Analytical Chemists (AOAC, 1970). Os compostos fenólicos totais foram extraídos pelo método de Goldstein e Swain (1963) e determinados pelo método de Folin Denis (AOAC, 1970). Os ácidos clorogênicos totais foram determinados segundo adaptação por Silva (1999) da técnica de Menezes (1990). A cafeína foi determinada segundo método colorimétrico (INSTITUTO ADOLFO LUTZ, 1985). A avaliação sensorial (prova de xícara ) foi determinada por provadores habilitados para tal.

As variáveis qualitativas dos grãos de café beneficiado e a produção foram submetidas à análise de variância, e para comparação entre médias das fontes, foi utilizado o teste de Tukey a $5 \%$ de probabilidade. Foram também realizados estudos de regressão, cujas equações foram ajustadas às variáveis em função das doses de cada fonte de $\mathrm{N}$.

\section{RESULTADOS E DISCUSSÃO}

\section{Produção de café}

As médias de produção (sacas de café beneficiado por hectare) para cada fonte de $\mathrm{N}$ são apresentadas na Tabela 1. Não foram observadas diferenças significativas entre as diferentes fontes e doses de $\mathrm{N}$, nem interação entre esses dois fatores. Verificou-se grande variabilidade entre as repetições em cada tratamento, o que provavelmente afetou os resultados da análise estatística.

\section{Qualidade do café}

\section{$\square$ Atividade enzimática da polifenoloxidase}

Pela avaliação da atividade enzimática da polifenoloxidase, observou-se que a interação entre fontes e doses de nitrogênio foi significativa $(P<0,05)$. A atividade enzimática da polifenoloxidase permite avaliar de modo objetivo a qualidade do café, que é diretamente proporcional à atividade dessa enzima (AMORIM e SILVA, 1968; CARVALHO et al., 1994).

TABELA 1 - Produção média (sacas de $60 \mathrm{~kg} \mathrm{ha}^{-1}$ de café beneficiado) em função de diferentes fontes e doses de $\mathrm{N}$.

\begin{tabular}{lc}
\hline \multicolumn{1}{c}{ Fontes de N } & Produção \\
\hline Calcionamida & 18,3 \\
Nitrato de potássio & 19,0 \\
Nitrocálcio & 24,9 \\
Sulfato de amônio & 19,9 \\
Uréia & 22,7 \\
Nitrato de amônio & 17,3 \\
\hline
\end{tabular}

O estudo de regressão das doses dentro de cada fonte de nitrogênio somente foi significativo avaliandose a atividade enzimática da polifenoloxidase nos cafeeiros adubados com as fontes nitrato de potássio, sulfato de amônio e nitrato de amônio, observando-se efeito quadrático com o aumento das doses de nitrogênio sobre a atividade da polifenoloxidase dos grãos de café beneficiados (Figura 1). As fontes sulfato de amônio e nitrato de amônio possibilitaram melhores respostas com as doses de $50\left(64,60 \mathrm{U} \mathrm{min}^{-1} \mathrm{~g}^{-1}\right.$ de amostra) e 121 $\mathrm{kg}$ de nitrogênio ha ${ }^{-1}\left(64,59 \mathrm{U} \mathrm{min}^{-1} \mathrm{~g}^{-1}\right.$ de amostra), respectivamente, e a partir dessas doses, nota-se redução da atividade da polifenoloxidase e, conseqüentemente, da qualidade do café. A fonte nitrato de potássio apresentou comportamento contrário, sendo a maior atividade da polifenoloxidase na maior dose aplicada $\left(65,19 \mathrm{U} \mathrm{min}^{-1} \mathrm{~g}^{-1}\right.$ de amostra).

\section{Acidez titulável total}

A interação entre fontes e doses de nitrogênio foi significativa $(\mathrm{P}<0,05)$. A avaliação da acidez titulável total tem boa correlação com a atividade da polifenoloxidase e, conseqüentemente, com a qualidade do café, sendo um instrumento auxiliar para a avaliação da qualidade, pois café de melhor qualidade apresenta menor índice de acidez (CARVALHO et al., 1994). O estudo de regressão das doses dentro de cada fonte de nitrogênio somente foi significativo para a fonte sulfato de amônio, em que se pode notar efeito linear prejudicial sobre a qualidade do café, em razão do aumento das doses de sulfato de amônio, com conseqüente aumento do 
índice de acidez (Figura 1). É interessante ressaltar que, pela avaliação da atividade enzimática da polifenoloxidase, menores doses de nitrogênio da fonte sulfato de amônio proporcionaram café de melhor qualidade, o que é condizente com o observado pela avaliação da acidez titulável total.

\section{Ácidos clorogênicos totais}

A interação entre fontes e doses de nitrogênio foi significativa $(\mathrm{P}<0,05)$ ao se avaliarem os teores de ácidos clorogênicos totais. Os ácidos clorogênicos são os principais compostos fenólicos do café, tendo esses uma relação inversa com a qualidade do café, ou seja, os maiores teores de ácidos clorogênicos totais podem ser encontrados em café de qualidade inferior (SILVA, 1999). O estudo de regressão das doses dentro de cada fonte de nitrogênio somente foi significativo quando se utilizaram as fontes nitrato de amônio e sulfato de amônio (Figura 1). Observou-se efeito negativo linear da fonte sulfato de amônio sobre a qualidade do café, pois à medida que se aumentavam as doses de nitrogênio, aumentavam-se também os teores de ácidos clorogênicos. Comportamento semelhante foi observado ao se analisar essa fonte por meio da acidez titulável, em que essa aumentava à medida que se aumentavam as doses desse fertilizante nitrogenado. Já o nitrato de amônio provocou comportamento contrário, atingindo o ponto de mínimo com a dose de $263 \mathrm{~kg} \mathrm{ha}^{-1}$ de nitrogênio (4,94\% de ácidos clorogênicos totais).

\section{Açúcares totais}

Por meio da avaliação da concentração de açúcares totais, observou-se que a interação entre fontes e doses de nitrogênio foi significativa $(\mathrm{P}<0,05)$. Os açúcares totais são mais elevados em grãos de café beneficiado que propiciam melhor qualidade de bebida, contribuindo para o sabor e aroma (CHAGAS, 1994; SILVA, 1999). O estudo de regressão das doses dentro de cada fonte de nitrogênio foi significativo quando se utilizaram as fontes calcionamida, nitrato de cálcio e sulfato de amônio, em que foi observado efeito quadrático nos teores de açúcares totais com o aumento das doses de nitrogênio. Verificou-se que os cafeeiros adubados com sulfato de amônio apresentaram as maiores concentrações de açúcares totais até a dose de $173 \mathrm{~kg} \mathrm{ha}^{-1}$ de N (7,23\% de açúcares totais), havendo redução da concentração a partir dessa dose (Figura 1). Com a calcionami- da, observou-se redução na concentração de açúcares totais à medida que se aumentavam as doses dessa fonte, atingindo um ponto de mínimo com $234 \mathrm{~kg} \mathrm{ha}^{-1}$ de nitrogênio $(5,69 \%$ de açúcares totais). $\mathrm{Na}$ fonte nitrato de cálcio, verificou-se aumento nos teores de açúcares totais até a dose de $190 \mathrm{~kg} \mathrm{ha}^{-1}(6,08 \%$ de açúcares totais), havendo redução nos teores desses açúcares após essa dose.

\section{$\square$ Compostos fenólicos totais}

Pela análise dos compostos fenólicos totais, observou-se que a interação entre fontes e doses de nitrogênio foi significativa $(\mathrm{P}<0,05)$. $\mathrm{O}$ estudo de regressão das doses dentro de cada fonte de nitrogênio somente foi significativo quando se utilizaram as fontes nitrato de amônio, nitrocálcio, nitrato de potássio e sulfato de amônio (Figura 1). A concentração de compostos fenólicos é inversamente proporcional à qualidade da bebida, sendo essa diretamente relacionada ao grau de ataque de microrganismos e ao estádio de maturação dos frutos (CARVALHO et al., 1989). As fontes nitrato de amônio e sulfato de amônio apresentaram efeito semelhante, havendo redução na concentração de compostos fenólicos totais, até as doses de 161 e $138 \mathrm{~kg} \mathrm{ha}^{-1}$ de nitrogênio, apresentando teores de compostos fenólicos totais, de 6,82 e $6,15 \%$, respectivamente, aumentando os teores desses compostos a partir dessas doses. Entretanto, cafeeiros adubados com as fontes nitrocálcio e nitrato de potássio apresentaram comportamento contrário, pois os teores de compostos fenólicos totais aumentaram até as doses de 200 e $154 \mathrm{~kg} \mathrm{ha}^{-1}$ de nitrogênio, apresentando concentração de 7,32 e $8,07 \%$ de compostos fenólicos totais, respectivamente, havendo redução na concentração desse composto após as referidas doses de nitrogênio dessas fontes.

\section{Cafeína}

Pela avaliação do teor de cafeína, observou-se que a interação entre fontes e doses de nitrogênio foi significativa $(\mathrm{P}<0,05)$. A cafeína é a principal purina na composição do café e encontra-se na polpa, no citoplasma do grão e ligada à parede celular. Sem dúvida, esse alcalóide tem papel importante como estimulante (MENEZES, 1990). O estudo de regressão das doses dentro de cada fonte de nitrogênio somente foi significativo quando se utilizou a fonte nitrato de potássio, tendo o incremento das doses proporcionado aumento linear da concentração de cafeína (Figura 1). 

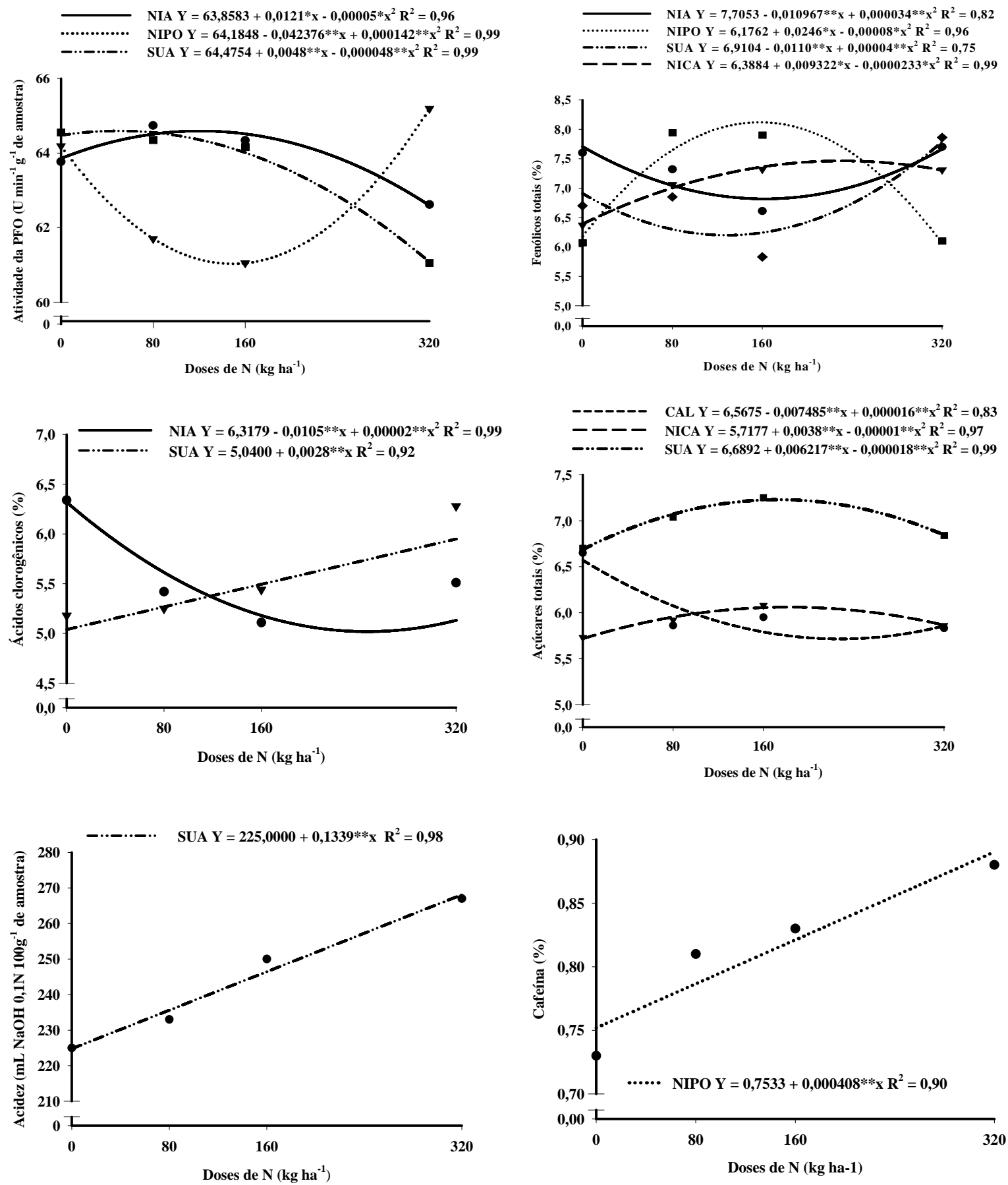

FIGURA 1 - Atividade enzimática da polifenoloxidase, compostos fenólicos totais, ácidos clorogênicos totais, açúcares totais, acidez titulável total e cafeína de grãos de café beneficiados, em função de diferentes fontes e doses de nitrogênio.

** e * Significativos a 1 e $5 \%$, respectivamente, pelo teste $\mathrm{F}$.

Ciênc. agrotec., Lavras. V.27, n.6, p.1246-1252, nov./dez., 2003 


\section{Prova de xícara}

Pela avaliação sensorial (prova de xícara), verificou-se que cafeeiros adubados com as fontes nitrocálcio e nitrato de amônio proporcionaram bebidas de menor qualidade, sendo classificada como dura. As demais fontes de $\mathrm{N}$ utilizadas proporcionaram bebida apenas mole (Tabela 2).

TABELA 2 - Avaliação sensorial de grãos de café beneficiados, em função de fontes de $\mathrm{N}$.

\begin{tabular}{ll}
\hline \multicolumn{1}{c}{ Fontes } & \multicolumn{1}{c}{ Prova de xícara } \\
\hline Sulfato de amônio & Bebida apenas mole \\
Calcionamida & Bebida apenas mole \\
Uréia & Bebida apenas mole \\
Nitrato de potássio & Bebida apenas mole \\
Nitrocálcio & Bebida dura \\
Nitrato de amônio & Bebida dura \\
\hline
\end{tabular}

\section{CONCLUSÕES}

Não houve resposta significativa da produção às fontes e doses de nitrogênio aplicadas.

Pela avaliação sensorial, cafeeiros adubados com nitrocálcio e nitrato de amônio proporcionaram bebida de menor qualidade.

Maiores doses de sulfato de amônio apresentaram efeito negativo sobre a composição química e qualidade dos grãos de café.

\section{REFERÊNCIAS BIBLIOGRÁFICAS}

AMORIM, H. V. Estado nutricional do cafeeiro e qualidade da bebida. Revista de Agricultura, Piracicaba, v. 43, n. 2, p. 93-103, jun. 1968.

AMORIM, H. V.; SCOTON, L. C.; CASTILHO, A.; PIMENTEL GOMES, F.; MALAVOLTA, E. Efeito da adubação NPK e orgânica na composição mineral do grão e qualidade da bebida. Anais da ESALQ, Piracicaba, v. 24, p. 215-227, 1967.

AMORIM, H. V.; SILVA, D. M. Relationship between the polyphenol oxidase activity of coffee beans and the quality of the beverage. Nature, New York, v. 219, n. 27, p. 381-382, July 1968 .
AMORIM, H. V.; TEIXEIRA, A. A.; MORAES, R. S.; REIS, A. J.; PIMENTEL GOMES, F.; MALAVOLTA, E. Efeito da adubação N, P e K no teor de macro e micronutrientes do fruto e na qualidade da bebida do café. Anais da ESALQ, Piracicaba, v. 30, p. 323-333, 1973.

ASSOCIATION OF OFFICIAL ANALYTICAL CHEMISTS. Official methods of analysis of the Association of Official Analytical Chemists. 11. ed. Washington, 1970. $1015 \mathrm{p}$

CARVALHO, V. D. de; CHALFOUN, S. M; CHAGAS, S. J. de R. Relação entre classificação do café pela bebida e composição físico-química, química e microflora do grão beneficiado. In: CONGRESSO BRASILEIRO DE PESQUISAS CAFEEIRAS, 15., 1989, Maringá. Anais... Maringá: MEC/IBC, 1989. p. $25-26$

CARVALHO, V. D. de; CHALFOUN, S. M.; CHAGAS, S. J. de R.; BOTREL, N.; JUSTE JÚNIOR, E. S. G. Relação entre a composição físico-química e química do grão beneficiado e qualidade de bebida do café. Pesquisa Agropecuária Brasileira, Brasília, v. 29, n. 3, p. 449-454, mar. 1994

CARVAlHO, V. D. de; CHAGAS, S. J. de R.; CHALFOUN, S. M. Fatores que afetam a qualidade do café. Informe Agropecuário, Belo Horizonte, v. 18, n. 187, p. 5-20, 1997.

CHAGAS, S. J. de R. Caracterização química e qualitativa de cafés de alguns municípios de três regiões produtoras de Minas Gerais. 1994. 83 f. Dissertação (Mestrado em Ciência dos Alimentos) - Universidade Federal de Lavras, Lavras, 1994.

CLIFFORD, M. N. Chemical and physical aspects of green coffee and coffee products. In: CLIFFORD, M. N.; WILLSON, K. C. Coffee, botany, biochemistry and production of beans and beverage. London: CROOMBELM, 1985. p. 305-359.

COMISSÃO DE FERTILIDADE DO SOLO DO ESTADO DE MINAS GERAIS. Recomendações para uso de corretivos e fertilizantes em Minas Gerais: $4^{\mathrm{a}}$ aproximação. Lavras: PETROBRÁS, 1989. 159 p.

DRAETTA, I. S.; LIMA D. C. Isolamentos e caracterização das polifenoloxidases do café. Coletânea do Instituto de Tecnologia de Alimentos, Campinas, v. 7, p. 3-28, 1976 
GOLDSTEIN, J. L.; SWAIN, T. Changes in tannins in ripening fruits. Phytochemistry, Oxford, v. 2, p. 371383, 1963.

INSTITUTO ADOLFO LUTZ. Normas analíticas, métodos químicos e físicos para análise de alimentos. 3. ed. São Paulo, 1985. v. 1, p. 190-192.

MALAVOLTA, E.; VITTI, G. C.; OLIVEIRA, S. A. Avaliação do estado nutricional das plantas. Piracicaba: POTAFOS, 1997. 319 p.

MENEZES, H. C. Variação dos monoisômeros e diisômeros do ácido cafeoilquínico com maturação de café. 1990. 171 f. Tese (Doutorado em Ciência dos Alimentos) - Universidade Estadual de Campinas, Campinas, 1990.

NELSON, N. A photometric adaptation of Somogy method for the determination of glucose. Journal of Biological Chemists, Baltimore, v. 153, n. 1, p. 375384, 1944.

PEREIRA, R. G. F. A. Efeito da inclusão de grãos defeituosos na composição química e qualidade do café (Coffea arabica L.) "estritamente mole". 1997. 96 f. Tese (Doutorado em Ciência dos Alimentos) - Universidade Federal de Lavras, Lavras, 1997.

PIMENTA, C. J. Qualidade do café (Coffea arabica L.) originado de frutos colhidos em quatro estádios de maturação. 1995. 94 f. Dissertação (Mestrado em
Ciência dos Alimentos) - Universidade Federal de Lavras, Lavras, 1995.

PONTING, J. D.; JOSLYNG, M. A. Ascorbic acid oxidation and browining in apple tissue extracts. Archives of Biochemistry, New York, v. 19, p. 47-63, 1948.

PRETE, C. E. C. Condutividade elétrica do exsudato

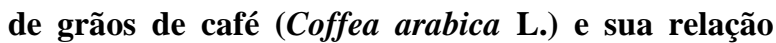
com a qualidade da bebida. 1992. $125 \mathrm{f}$. Tese (Doutorado em Fitotecnia) - Escola Superior de Agricultura "Luiz de Queiroz", Piracicaba, 1992.

SANTINATO, R.; OLIVEIRA, L. H.; PEREIRA, E. M. Efeitos do uso de salitre de potássio como fonte de nitrogênio e potássio na adubação química do cafeeiro: Carmo do Paranaíba/MG-1992-1996. In: CONGRESSO BRASILEIRO DE PESQUISAS CAFEEIRAS, 22., 1996, Águas de Lindóia. Anais... Águas de Lindóia: SDR/PROCAFÉ/EMBRAPA/ DENAC/CATI, 1996. p. 180-184.

SILVA, E. B. Potássio para o cafeeiro: efeito de fontes, doses e determinação de cloreto. 1995.87 f. Dissertação (Mestrado em Ciência do Solo) - Universidade Federal de Lavras, Lavras, 1995.

SILVA, E. B. Fontes e doses de potássio na produção e qualidade do café provenientes de plantas cultivadas em duas condições edafoclimáticas. 1999. 105 p. Tese (Doutorado em Ciência do Solo) - Universidade Federal de Lavras, Lavras, 1999. 